\title{
Dokuz Eylül Üniversitesi Tıp Fakültesinde Akran Danışmanlığı Programı: İki Yıllık Deneyim
}

\section{Peer mentoring program in Dokuz Eylul Faculty of Medicine: A two-year experience}

Berna Musal*

*Tıp Eğitimi AD, Akran Danışmanlığı Programı Koordinatörü ve Danışmanı

\author{
Anahtar Sözcükler: \\ Akran danışmanlığı, \\ tıp fakültesi öğrencisi \\ Keywords: \\ Peer mentoring, \\ medical student \\ Gönderilme Tarihi \\ Submitted:19.09.2018 \\ Kabul Tarihi \\ Accepted: 31.10 .2018
}

\section{ÖZET:}

Dokuz Eylül Üniversitesi Tip Fakültesinde Dönem 1 öğrencilerinin fakülte ve eğitim sistemine uyumlarını kolaylaştırmak amacıyla akran danışmanlığ́ programı geliştirilmiş ve uygulanmaya başlanmıştır. $\mathrm{Bu}$ makalede akran danışmanlığı programına ilişkin iki yıllık deneyimin paylaşılması amaçlanmıştır. Akran danışmanlığının Dönem 1 öğrencilerine fakülte ve eğitim sistemine uyum konusunda önemli katkılar sağladığı, deneyimler ve geribildirimler ş̧ığında geliştirilerek sürdürülmesi gerektiği düşünülmektedir.

\section{ABSTRACT:}

In Dokuz Eylul University Faculty of Medicine, peer mentoring program has been developed and introduced with the aim of providing support to first year medical students for adaptation to faculty and educational system. The aim of this paper is to share the two-year experience of peer mentoring program. It is thought that, peer mentoring program has provided an important contribution to first year medical students for adaptation to faculty and educational system and it should be developed and carried on in the light of feedback and experiences.

\section{GÍRIŞ}

Tıp fakültelerinde öğrencilerin akademik, sosyal, kariyer gelişimleri açısından farklı uygulamalar ve yöntemlerle desteklenmesi önem taşımaktadır 1-3. Tıp Fakültesine yeni başlayan öğrencilerin fakülte ortamı ve sürdürülen eğitim programına uyum sağlama güçlüğü yaşayabildikleri bilinmektedir. Dokuz Eylül Üniversitesi Tıp Fakültesi program değerlendirme çalışmaları kapsamında fakülteye yeni başlayan öğrencilere her yıl uygulanan anket çalışmalarında başlangıç aşamasında eğiticiler ve üst sınıflarda okuyan akranlarından destek gereksinimi duydukları saptanmıştır4-5.

Makale Künye Bilgisi: Musal B (2018), Dokuz Eylül Üniversitesi Tıp Fakültesinde Akran Danışmanlı̆̆ı Programı: İki Yıllık Deneyim Tıp Eğitimi Dünyası. 53, 5-12. 
Akran danışmanlığ 1 , kişisel, sosyal ve akademik konularda akranlarına yardım etmeleri için seçilen kişilerin, yani akran danışmanlarının, amaca yönelik olarak eğitim aldıkları ve eğitim sonrasında sundukları danışmanlıkla ilgili gözetim ve denetim desteği aldıkları bir süreç olarak tanımlanmaktadır6. Akran danışmanlığı sosyal destek, öğrenme süreçlerinin kolaylaştııılması, kariyer danışmanlığı gibi amaçlara yönelik olarak yapılandırılmaktadır7-8. Farklı tıp fakültelerinde yeni başlayan öğrencilerin uyum süreçlerini kolaylaştırmak amaciyla üst sınıflardaki öğrencilerin yeni başlayan öğrencileri desteklediği akran danışmanlığı uygulama örnekleri bulunmaktadır9-11. Dokuz Eylül Üniversitesi Tip Fakültesine başlayan Dönem 1 öğrencileri ile üst sınıflardaki danışman öğrencileri, danışman öğretim üyeleri rehberliğinde bir araya getirerek, yeni öğrencilerin fakülte ve eğitim sistemine uyumlarını kolaylaştırmak amacıyla 2016 y1lında akran danışmanlığı programı geliştirilmiş ve fakülte kurulu onayı ile uygulanmaya başlanmıştır. Bu makalede akran danışmanlığı programına ilişkin iki yıllık deneyimin paylaşılması amaçlanmıştır.

\section{Akran Danışmanlığı Yöntemi ve Uygulama Şekli}

Akran danışmanlığı plan ve uygulama aşamaları akran danışmanlığı yönetim ekibi tarafından yürütülmektedir. Ekip, Tıp Eğitimi Öğrenci Kurulu (TEÖK) üyelerinden oluşmaktadır (Ek 1. Yönetim ekibi üye listesi). Yönetim ekibi, Tıp Eğitimi Anabilim Dalı Başkanı koordinatörlüğünde ve Dönem 1 kurul başkanı ile bağlantılı olarak çalışmaktadır. Ekip, akran danışmanı adaylarının seçim, eğitim, izlem çalışmalarını ve danışmanlık etkinliklerini raporlama görevlerini üstlenmiştir. Her yarıyıl sonunda Dekanlığa iletilmek üzere değerlendirme raporu hazırlamaktadır.

Akran danışmanı olmak isteyen üst sınıflardaki öğrencilerin Ağustos ayı sonunda doldurdukları başvuru formları yönetim ekibi tarafından akademik y1l başında adaylarla görüşme yapılarak değerlendirilmektedir. Danışmanlık görevi üstlenenlerin özellikle geribildirim, dinleme becerileri gibi iletişim becerilerine sahip olması gerektiği bilinmektedir12. Akran danışmanı adayları Eylül ayının ilk haftalarında yönetim ekibi tarafından düzenlenen liderlik, iletişim becerileri, kriz yönetimi, stres yönetimi, zaman yönetimi, motivasyon, problem çözme ve öğrenme stratejileri konularında eğitim almaktadırlar.

Akran danışmanları, Dönem 1 öğrencilerine danışmanlık yapan Dönem 1 kurulunda görevli öğretim üyeleriyle eşgüdüm halinde çalışmaktadır. Her danışman öğretim üyesine iki akran danışmanı düşecek şekilde planlama yapılmaktadır. Bu nedenle uygulama öncesinde akran danışmanları ve Dönem 1 danışman öğretim üyeleri bir araya gelerek tanışma, rol ve sorumluluklar tanımlanmaktadır.

\section{Akran danışmanlarının sorumlulukları;}

$\sqrt{ }$ Her yarıyılda en az bir kez akran danışmanıdanışan görüşmesi yapma, danışanlar tarafından ulaşılabilir olma ve gereksinimler doğrultusunda danışan öğrenciye destek olma, gerektiğinde sorunları danışman öğretim üyelerine ileterek destek isteme,

$\sqrt{ }$ Danışman öğretim üyelerinin Dönem 1 öğrencileriyle her yarıyılda en az birer kez yaptıkları görüşmelerde bulunarak aktif katılım ve destek sağlama,

$\sqrt{ }$ Danışan öğrencilerin iletişim bilgileri, görüşme tarihi, danışan istekleri, sorunlar ve çözüme yönelik çalışmalar, planlar gibi bilgileri izlem formuna (Ek 2) uygun şekilde kapsayan dosya hazırlama, 
$\sqrt{ }$ Her yarıyıl sonunda akran danışmanlığı yönetim ekibine dosyada yer alan bilgileri ve önerilerini içeren rapor sunma şeklinde tanımlanmıştır.

\section{Değerlendirme ve Sonuç}

Programın ilk yılı amaca uygun şekilde tamamlanmış olup, akran danışmanları tarafindan yılda iki kez hazırlanan raporlar akran danışmanlığı yönetim ekibi üyelerince bir araya getirilerek Dekanlığa sunulmuştur. Yıl sonunda akran danışmanları ve danışanların yazılı ve sözlü geri bildirimleri alınarak değerlendirilmiştir.
2017-2018 akademik y1lında önceki yılın deneyimleri ve geribildirimleri doğrultusunda, Dönem 1 programında akran danışmanlığı etkinliklerine danışmanlara da uygun olan tarihlerde yer ayrılması, etkinliklerin erken başlatılması gibi düzenlemeler yapılmıştır. Bir önceki yıldaki gibi "Dönem 1 öğrencilerinin akran danışmanlarına ilettikleri sorunlar, Dönem 1 öğrencilerinin sorunlara yönelik çözüm önerileri, akran danışmanlarının öğrencilere yaptıkları öneriler ve akran danışmanlığına yönelik öneriler" başlıkları altında hazırlanan iki değerlendirme raporu Dekanlıkla paylaşılarak

\section{TABLO 1. Dönem 1 Öğrencilerinin* Danışmanlık Öğelerine İlişkin Geri Bildirimleri}

\begin{tabular}{|c|c|c|c|}
\hline & \multicolumn{2}{|c|}{ ORTALAMA PUAN** } & \multirow[t]{2}{*}{ P değeri ${ }^{\star \star \star *}$} \\
\hline $\begin{array}{l}\text { DEĞERLENDİRİLEN } \\
\text { ÖĞELER }\end{array}$ & $\begin{array}{l}\text { 2016-2017 } \\
\text { n:143 }\end{array}$ & $\begin{array}{l}\text { 2017-2018 } \\
\text { n:139 }\end{array}$ & \\
\hline $\begin{array}{l}\text { Danışman öğretim üyesinin } \\
\text { etkinliği }\end{array}$ & $3.56 \pm 1.28$ & $3.53 \pm 1.17$ & 0.892 \\
\hline Akran danışmanının etkinliği & $3.42 \pm 1.36$ & $4.28 \pm 1.04 \uparrow$ & 0.000 \\
\hline $\begin{array}{l}\text { Akran danışmanı ile kurulan } \\
\text { iletişim }\end{array}$ & $3.33 \pm 1.37$ & $4.32 \pm 1.10 \uparrow$ & 0.000 \\
\hline $\begin{array}{l}\text { Akran danışmanının } \\
\text { beklentileri karșılaması }\end{array}$ & $3.08 \pm 1.39$ & $4.28 \pm 1.12 \uparrow$ & 0.000 \\
\hline $\begin{array}{l}\text { Genel olarak danışmanlık } \\
\text { hizmetinin değerlendirilmesi }\end{array}$ & $3.08 \pm 1.30$ & $4.03 \pm 1.09 \uparrow$ & 0.000 \\
\hline
\end{tabular}

*2016-2017 y1lında 143, 2017-2018 akademik y1lında 139 öğrenci (\%41.9 ve \%41.1) geri bildirim vermiştir.

**Öğeler 1-5 puan (1:en az, 3:orta, 5:en çok) arasında değerlendirilmiştir.

*** İki ortalama arasındaki farkın önemlilik testi 
TABLO 2. Akran Danışmanlarının* Danışmanlık Öğelerine İlişkin Geri Bildirimleri

\begin{tabular}{|l|l|l|l|}
\hline \multirow{2}{*}{$\begin{array}{l}\text { DEGĞERLENDİRILEN } \\
\text { OGELER }\end{array}$} & \multicolumn{2}{|l|}{ ORTALAMA PUAN } & $\begin{array}{l}\text { P } \\
\text { değeri*** }\end{array}$ \\
\cline { 2 - 3 } & $\mathbf{2 0 1 6 - 2 0 1 7}$ & $\mathbf{2 0 1 7 - 2 0 1 8}$ & \\
\hline Sürecin başında alınan eğitim & $4.71 \pm 0.61$ & $4.28 \pm 1.00$ & 0.188 \\
\hline $\begin{array}{l}\text { Danışman öğretim üyesiyle } \\
\text { ișbirliği }\end{array}$ & $4.07 \pm 1.07$ & $3.55 \pm 1.37$ & 0.292 \\
\hline Kendi yeterlik algıs1 & $4.21 \pm 0.58$ & $4.27 \pm 1.19$ & 0.873 \\
\hline $\begin{array}{l}\text { Danışanların akran } \\
\text { danışmanlığına yaklaşımı }\end{array}$ & $3.21 \pm 0.97$ & $3.82 \pm 1.33$ & 0.202 \\
\hline $\begin{array}{l}\text { Genel olarak akran danışmanlığ1 } \\
\text { uygulamasının değerlendirilmesi }\end{array}$ & $3.93 \pm 0.47$ & $4.46 \pm 0.16 \uparrow$ & 0.015 \\
\hline
\end{tabular}

*2016-2017 yılında 20, 2017-2018 y1lında 26 akran danışmanı görev yapmış ve geribildirim vermiștir.

**Öğeler 1-5 puan (1:en az, 3:orta, 5:en çok) arasında değerlendirilmiştir.

***iki ortalama arasındaki farkın önemlilik testi

değerlendirilmiştir. Dönem 1 öğrencileri ve akran danışmanlarının 2016-2017 ve 2017-2018 akademik yıl sonu geri bildirim bulguları Tablo 1 ve 2 'de sunulmaktadır.

Dönem 1 öğrencilerinin geribildirim dönüşleri istenen düzeyde olmamakla birlikte bulgular değerlendirildiğinde; akran danışmanlığ öğeleri ve danışman öğretim üyelerine ilişkin verdikleri puan ortalamalarının her iki yılda 3.08-4.32 arasında olduğu, akran danışmanının etkinliği, akran danışmanı ile kurulan iletişim, akran danışmanının beklentileri karşılaması ve genel olarak danışmanlık hizmetine ilişkin verdikleri puanların 2018 yllında bir önceki yıla göre istatistiksel açıdan anlamlı derecede arttığı saptanmıştır. Akran danışmanlarının akran danışmanlığı öğeleri ve danışman öğretim üyesiyle iletişime verdikleri puan ortalamalarının her iki yılda 3.21-4.71 arasında olduğu, genel olarak akran danışmanlığ uygulamasının değerlendirilmesi puanlarının 2018 yılında bir önceki yıla göre istatistiksel açıdan anlamlı derecede yüksek olduğu saptanmıştır. Ayrıca, 2017-2018 akademik yılının Aralık ayında yeni başlayan öğrencilerin görüş ve önerilerinin araştırıldığı anket formuna 255 öğrenci (\%75.4) yanıt vermiş olup, akran danışmanlığından yararlanma düzeylerine ilişkin ek soruya öğrencilerin \%28.6's1 çok yararlandım, \%43.2'si yararlandım; \%28.2'si yararlanmadım şeklinde yanıt vermiştir. Üst sınıf öğrencilerin akran danışmanlığı rolleri üstlenmelerinin kendi gelişimlerini de olumlu yönde etkilediği belirtilmektedir13. Akran danışmanlığı yönetim ekibinin ve akran danışmanlarının motivasyonlarının ve süreci sahiplenmelerinin; Dönem 1 öğrencilerinin hoşnutluk düzeyleri, programın uygulanması ve geliştirilmesini olumlu yönde etkilediği düşünülmektedir. Ek 2 ve Ek 3'de Dönem 1 ve akran danışmanı öğrencilerin yazılı geribildirimlerinden örnekler yer almaktadır.

Geribildirimler, deneyimler ve önerileri kapsayan raporlar değerlendirilerek programın geliştirilmesi amaciyla düzenlemeler ve Dönem 1 öğrencilerini destekleyecek uygulamalar yapılmaktadır. Örneğin, Dönem 1 öğrencilerinin ve danışmanların ilk yıl geribildirimlerinde yer alan, etkinliğin daha erken başlatılması önerisi doğrultusunda 2017-2018 akademik 
y1lından itibaren Dönem 1 açı1ış haftası, akran danışmanları ve yeni gelen öğrencilerin bir araya gelerek akran danışmanlığının amacının ve karşı1ıklı beklentilerin tanımlanması, soruların yanıtlanması ve sağlık kampüsü gezisi şeklinde başlatılmaktadır. Yıl içinde akran danışmanlarının yönlendirmesiyle gereksinimi olan Dönem 1 öğrencileri belirlenerek psikolojik ve tıbbi destek almaları sağlanmıştır.

Sonuç olarak; akran danışmanlığının Dönem 1 öğrencilerine özellikle fakülte ve eğitim sistemine uyum konusunda katkılar sağladığı, genel olarak danışanların hoşnutluk düzeylerinin ikinci yılda arttığı ancak öğrencilerin bir kısmının bu etkinlikten yararlanmadığ 1 , geribildirimde bulunmadığı ve daha fazla öğrencinin yararlanmasına yönelik çaba gerektiği anlaşılmıştır. Uygulamanın önümüzdeki yıllarda deneyimler ve geribildirimler 1şığında geliştirilerek sürdürülmesi planlanmaktadır.

\section{KAYNAKLAR}

1. Vogan CL, McKimm J, Da Silva AL, Grant A. Twelve tips for providing effective student support in undergraduate medical education. Medical Teacher 2014; 36: 480-485.

2. Eaton DGM, Levene MI. Formal appraisal of undergraduate medical students: is it worth the effort. Medical Teacher 2004; 26 (1): 28-32.

\section{Ho Y, Kwon OY, Park SY, Yoon TY. A study} of satisfaction of medical students on their mentoring programs at one medical school in Korea. Korean Journal of Medical Education 2017; 29 (4): 253-262.

4. Tımbıl S, Özan S, Velipaşaoğlu S, Gürsel Y, Taşkıran C, Musal B. Tıp eğitimine yeni başlayan öğrencilere yönelik durum değerlendirme çalışması: İki yıla ait verilerin karşılaştırılması. Tıp Eğitimi Dünyası Ekim 2007; 26: 1-12.
5. Musal B, Taskıran C, Gursel Y, Ozan S, Tımbıl S, Velipaşaoğlu S. An example of program evaluation project in undergraduate medical education. Education for Health, 2008; 21 (1):113.

6. Aladağ M, Tezer E. Akran danışmanlığı nedir? Ne değildir? Türk Psikolojik Danışma ve Rehberlik Dergisi 2007; 27 (3): 139-155.

7. Taylor SJ, Faghri S, Aggarwal N, Zeller K, Dollase R, Reis SP. Developing a peer-mentor program for medical students. Teaching and Learning in Medicine 2013; 25 (1) : 97-102.

8. Fischer BB, Herta DK. Formal mentoring programmes for medical students and doctors-a review of the Medline literatüre. Medical Teacher 2006; 28 (3): 248-257.

9. University of Connecticut School of Medicine Mentoring Programs.

https://medicine.uconn.edu/about-us/academicaffairs/mentoring-programs/

10. University of Iowa Health Care-Carver College of Medicine Peer Mentoring Program. https://medicine.uiowa.edu/md/student-support/ student-counseling/peer-mentoring-program

11. LSU Health New Orleans School of Medicine Medical School Support Services. https://www.medschool.1suhsc.edu/cmhe/ programs_medical_school_support.aspx

12. Ramani S, Gruppen L, Kachur EK. Twelve tips for developing effective mentors. Medical Teacher 2006; 28 (5): 404-408.

13. Peters H, Zdravkovic M, Costa MJ, Celenza A, Ghias K, Klamen D, Mossop L, Rieder M, Nadarajah VD, Wangsaturaka D, Wohlin M, Weggemans M. Twelve tips for enhancing student engagement. Medical Teacher April 2018. DOI: $10.1080 / 0142159 x .2018 .1459530$ 
EK 1. Akran danışmanlığı yönetim ekibi üye listesi

2016-2017 dönemi: Gamze Gültekin, Duygu Engez, Anıl Palut, Kaan Durmuş, Merve Birge

2017-2018 dönemi: Elifnaz Öztürkoğlu, Gamze Gültekin, Duygu Engez, Kaan Durmuş, Nida Gülpınar, Sedenay Sifil

EK 2. Akran Danışmanlığı İzlem Formu

Akran Danışmanları:

Görüşme tarihi:

\begin{tabular}{|c|c|c|c|c|}
\hline Öğrencinin Adı & $\begin{array}{ll}\text { Görüşme } & \text { ile } \\
\text { İlgili } & \\
\text { Genel Notlar } & \end{array}$ & $\begin{array}{l}\text { Danışan } \\
\text { Tarafından } \\
\text { İletilen } \\
\text { Sorunlar }\end{array}$ & $\begin{array}{l}\text { Danışan } \\
\text { Tarafindan } \\
\text { İletilen } \\
\text { Görüş } \\
\text { Öneriler }\end{array}$ & $\begin{array}{l}\text { Akran } \\
\text { Danışmanı } \\
\text { Tarafindan } \\
\text { Yapılanlar- } \\
\text { Öneriler }\end{array}$ \\
\hline & & & & \\
\hline 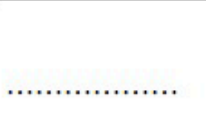 & & & & \\
\hline
\end{tabular}




\section{EK 3. Dönem 1 Öğrencilerinin Akran Danışmanlığına İlişkin Yazılı Geribildirimlerinden Örnekler (Haziran 2018)}

$\sqrt{ }$ Yeni bir çevreye gelip alışmaya çalışan kişiler için yararlı ve yeterli bir uygulamaydı.

$\sqrt{ }$ Danışmanlarımıza daha az öğrenci verilirse daha rahat ve kolay ilişki kurulabilir.

$\checkmark$ Gayet yeterli ve devam etmesi gereken bir sistem.

$\checkmark$ Çok iyi bir uygulama bence devam etmeli.

$\sqrt{ }$ Çok güzel bir uygulama. Gelecek senelerde ben de akran danışmanı olmak isterim.

$\sqrt{ }$ Dönem 1'lere yardımcı olması bakımından gayet iyi bir uygulama. İlerde de bu şekilde devam etsin.

$\sqrt{ }$ Şehri ve okulu hiç bilmeyen öğrencilere, tecrübeli öğrencilerin ve hocanın yardım etmesi güzel bir şey.

$\sqrt{ }$ Zorunlu toplantılar haricinde çok yararlı bir sistem. Özellikle ilk aylarda kafamıza takılan şeylere yanıt bulmakta çok yardımcı oldu.

$\sqrt{ }$ Akran danışmanlarımızla kolay ve rahat bir iletişim sağladık. Bu bizim sorularımızı kolayca sorup yararlı cevaplar almamızı sağladı.

$\sqrt{ }$ Özellikle ilk günlerde çok faydalı olduğunu düşünüyorum, akran danışmanlarımız da çok tatlıydı bu iş için çok iyiydiler. Ama okulun akran danışman toplantısı şeklinde zorunlu kıldığı toplantıları mantıklı bulmuyorum, bence biz danışmanlarımızla arkadaşlık çerçevesi içinde gayet iyi iletişim kurabiliyoruz.

$\sqrt{ }$ Okula adapte olma açısından çok yardımcı oldular ve hep yeni bir bilgi sundular her şey için teşekkür ederiz

$\sqrt{ }$ İyiydi okula alışmamızı sağladılar.

$\sqrt{ }$ Dönem 1'e adapte olmaya çalışan bizler için iyi bir uygulama

$\sqrt{ }$ Çok güzel bir uygulama olduğunu düşünüyorum. Akran danışmanlarımıza her zaman ulaşabildik, aklımıza takılan pek çok soruyu sorma imkanımız oldu.

$\sqrt{ }$ Bize zamanlarını ayırıp ilgilendikleri için teşekkür ederiz. Okula alışma sürecimizi hızlandırdılar. $\sqrt{ }$ Danışman hocamızla hiç tanışmadım kendisi yurtdışındaydı ancak akranlarım bu açığı yeterince kapattı ikisine de çok teşekkür ederim. Bence akran danışmanlı̆̆ gerçekten yararlı bir uygulama. Akran danışmanlarımız bize her konuda çok yardımcı oldular çok memnunum.

$\sqrt{ }$ Akran danışmanlığı zorunlu bir buluşma gibi gösterilmezse insanlar daha hoşnut olabilir, danışmana ihtiyacı olmadığını hisseden birisi zaten danışmanla konuşsa bile önyargısı sebebiyle faydalanamaz. Danışmanlık buluşmaları (danışman hocanın olmadı̆ğ buluşmalar) zorunlu tutulmamalı ancak iyi duyurulmalı.

$\sqrt{ }$ Akranlarımız bize çok yardımcı oldular, kafamızdaki hiçbir soruyu cevapsız bırakmadılar. Hem çok iyi abla ve abi oldular hem de çok iyi arkadaş oldular, alışma sürecime çok katkısı oldu.

$\sqrt{ }$ İlk geldiğimizde hiçbir şeyle ilgili bilgimiz olmuyor ve bu bizi tedirgin ediyor. Ama akran danışmanlarımız olduğu için ne zaman istersek onlara mesaj atarak bile sorularımızın cevaplarını alabildik. Bence çok yararlı ve güzel bir uygulama.

$\sqrt{ }$ Bence çok faydalı bir uygulama. İyi düşünülmüş ve tasarlanmış.

$\sqrt{ }$ Birçok sorunumuza çözüm bulduğumuz ve her zaman ulaşabileceğimiz insanlarla tanıştığımız gayet yararlı bir uygulamayd. 


\section{EK 4. Akran Danışmanlarının Yazılı Geribildirimlerinden Örnekler (Haziran 2018)}

$\sqrt{ }$ Akran danışmanlığı fakülteye yeni gelenler için çok yararlı ve güzel bir uygulama. Bu uygulamada daha fazla kişinin danışman olması sağlanabilir. Bunu akranlarımdan aldığımız geri bildirimlerde gördük. Danışman sayısı artarsa akranlarımıza daha yararlı olabiliriz

$\sqrt{ }$ Oldukça verimli, okulu sevdirici ve samimi bir uygulama.

$\sqrt{ }$ Resmiyetinden daha çok arkadaş-arkadaş konuşmaları gibi ilerleyen bir akran danışmanlığı çok daha iyi olurdu. Evrak işi gereksiz

$\sqrt{ }$ Görüşmeler daha sistematik yapılabilir. Öğrencilerin programlarına uygun bir şekilde. Onun dişında güzel gidiyor her şey.

$\sqrt{ }$ Hiçbirşey bilmeden okulumuza gelen dönem 1 arkadaşlarımız için eğitici, tanıtıcı güzel bir program, akranlarım memnun kaldılar. Katılımın daha fazla olması için kafa yorulması gerektiğini düşünüyorum. Parçası olduğum için mutluyum teşekkürler. Akran danışmanlığı yeni öğrencilere tahmin ettiklerinden fazlasını katıyor ama bunun için önce katılımlarını gerçekleştirmek lazım. Katılım yüzdesi geçen yıldan çok fazla olmasına rağmen bence daha da artabilir.

$\sqrt{ }$ Dönem 1 öğrencileri için çok faydalı olduğunu düşünüyorum. Okulun ilk gününden itibaren yardım alacakları, sorunlarına çözüm bulacakları insanlar olmaya çalıştık. Bir çoğu bu programdan çok fazla faydalandı. Özellikle ders çalışma, sınav sistemi, PDÖ’ye uyum sağlama konusunda onlara yol gösterici olduğumuza inanıyorum. Bu uygulama hem danışan hem de danışman için çok faydalıydı. Yılın başında danışman olarak aldığımız eğitimler kişisel gelişimimize ve dönem 1 öğrencilerine olan yaklaşımımıza çok fayda sağladı. 